Marina Rodrigues Miranda' https://orcid.org/0000-0002-II33-7827

Fernanda Monteiro Barreto Camargo²

https://orcid.org/0000-000 I-8339-49I I

Fábio Guss Strelhow ${ }^{3}$

https://orcid.org/0000-0002-2986-1563

\title{
Tupiabá: cartas do mundo para os(as) guardiões(ãs) da terra
}

Aldeia Tupiabá, Cô-pixaba/ES, 25 de maio de 2020.

Saudações!

Olá, camaradas professores(as) do Brasil e do mundo. Tudo bem com vocês? Esperamos que estejam bem, mesmo estando confinados em casa e sem perspectivas de retorno às atividades docentes e a outras pertinências laborais.

Esta carta é uma tentativa de diálogo, para minimizar os impactos que sofremos pela interrupção abrupta da nossa liberdade. No entanto, nossos corpos dóceis e adestrados permanecem em casa, em constante atividade. Estamos reflexivos com este novo tempo, um tempo não conciliado

\footnotetext{
' Doutora em Educação pela Universidade Federal da Bahia - UFBA. Professora do Curso de Licenciatura Interdisciplinar em Ciências Sociais e suas Tecnologias e da Pós-graduação em Agroecologia e Educação do Campo da Universidade Federal do Sul da Bahia - UFSB. Professora do Curso de Licenciatura Intercultural Indígena da Universidade Federal do Espírito Santo - UFES. Líder do Núcleo de Pesquisa, Ensino e Extensão em Experiência do Sensível - NUPEEES/UFSB. E-mail: marinarmiranda@gmail.com

${ }^{2}$ Doutora em Educação pela Universidade Federal do Espírito Santo - UFES. Professora do Departamento de Linguagens, Cultura e Educação - Centro de Educação/UFES. Líder do Grupo de Pesquisa, Imagens, Tecnologias e Infâncias - GEPITI. Membra do Núcleo de Pesquisa, Ensino e Extensão em Experiência do Sensível NUPEEES/UFSB. E-mail: fmbcamargo@gmail.com

${ }^{3}$ Pós-graduado em Educação Especial e Inclusiva. Professor da Educação Básica na rede pública do Município de Cariacica/ES. Membro do Núcleo de Pesquisa, Ensino e Extensão em Experiência do Sensível - NUPEEES/ Universidade Federal do Sul da Bahia - UFSB. E-mail: fabio.guss@hotmail.com
} 
às nossas expectativas. Ressalvo as palavras poéticas de Ivan Lins, que são narrativas importantes ao contínuo desta conversação: [...]"No novo tempo, apesar dos perigos... Da força mais bruta, da noite que assusta, estamos na luta... Pra sobreviver, pra sobreviver, pra sobreviver... Pra que nossa esperança seja mais que a vingança... Seja sempre um caminho que se deixa de herança” [...] (LINS, 1984).

Perigo, luta e herança são palavras-força desta composição e adequam-se a este espaço/tempo de outrora anunciado e não atentado por nossas cegueiras, surdez e mudez frente aos apelos dos marginalizados, atropelados por nossas rotinas adestradas e caducas. Conscientes e imersos nesta crise, há de se bradar ainda mais forte em oposição às políticas socioambientais que estão sendo cooptadas. Nosso ativismo deve permanecer lutando pelo respeito às diferenças culturais e contribuindo para fomentar processos dialogantes e fecundos para a promoção de vidas equânimes.

A sugestão, por hora, é o caminhar para si, desobstruindo processos no alcance às dimensões do humano, retomando as conectividades no âmago familiar, consagrando dignidades aos elos que foram perdidos pela nossa sobrecarga de trabalho, compondo processos de conhecimentos em comunalidade.

Nesse âmbito, nunca, como nos dias que passam, o bem viver inspirado nos movimentos dos povos originários foi tão bem-vindo. Os indígenas afirmam que são "povos do presente". Eles vivem o tempo-momento-instante sem aligeirar o amanhã. $O$ tempo indígena - Kairós -sintoniza outras orbis para além dos materiais. $O$ tempo indígena é um tempo espiritual, sustentado na ancestralidade.

E nós? Somos hoje, todos nós, povos do presente? Ou o amanhã ainda pulsa em nossas veias?

Por incrível que pareça, estamos em estado de apatia. E, mesmo conectados, o nosso sentimento é de uma impotência virtual e presencial generalizada. Essa anacronia nos remete à mesma cantada por Gil na década de noventa.

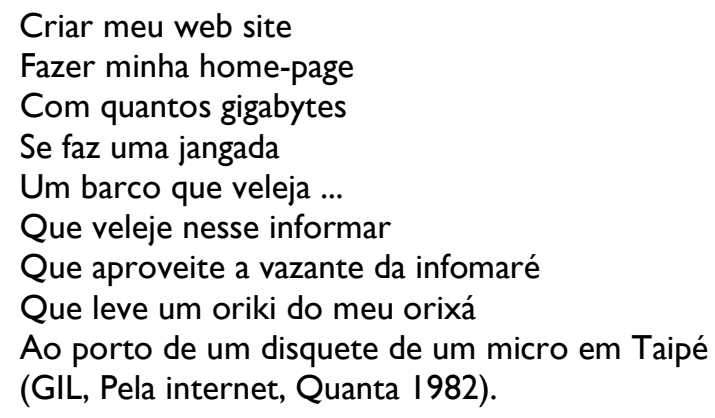

Um outro modo de navegar nesse tempo de pandemia compôs nosso Tupiabá, um projeto coletivo docente. São professores(as) pesquisador(e)as do Núcleo de Pesquisa, Ensino e Extensão em Experiência do Sensível (NUPEEES/UFSB) e do Grupo de Pesquisas, Tecnologias e Infâncias (GPITI/UFES). Constituímo-nos numa aldeia, com o intuito de agregar os conhecimentos apreendidos 
com os povos indígenas do Sul da Bahia e do Espírito Santo, alinhando as maestrias de saberes originários articulados as suas cosmogonias Etnoecológicas como sustentáculo da existência planetária.

Nessas redes Tucumã nos conectamos ao bem-viver da aldeia do Pé do Monte, na pulsante oralidade Patxohã, revitalizada na Kijêtxawe Txihihãy Pataxó Ãpaká Txó Egnetopne (Escola Indígena Pé do Monte), a fim de partilhar as experiências sensíveis de origens do conhecimento da cultura Pataxó, que nos inspiraram na nossa própria construção identitária.

Ao escrevermos esta carta aos nossos interlocutores, temos, como sentimento, o desejo de construir um entrelaço revitalizador da nossa própria cultura na identidade indígena, no intuito de conhecer suas cosmologias, para que possamos atravessar estes tempos pandêmicos, cobertos por outras divindades criadoras, compondo experiências, tecendo novos caminhos e constituindo nossas próprias singularidades.

Assim fomos percebendo, ao longo do tempo nas aldeias, que a política de interação dos indígenas com a sociedade se pratica culturalmente por escrita de cartas, gênero narrativo que se produz com a escrita de autoria coletiva. Geralmente, o teor dessas cartas exprime e denuncia as violações de direitos que esses povos têm sofrido ao longo do tempo e reafirma os dados reivindicatórios, que são os princípios basilares dos discursos aldeados. A organização desse conhecimento é realizada por um(a) indígena, filho(a) da aldeia, que irá realizar a transposição/tradução da oralidade da comunidade para o discurso escrito.

Essa traduzibilidade do conhecimento oral para um suporte discursivo da escrita de uma carta aporta a essência performática dos conhecimentos de origens identitárias do povo que teceu a escrita. No nosso caso específico, as experiências sensíveis que nos remetem a esta discussão foram vividas com as etnias Pataxó, Tupiniquim e Guarani. A carta, de autoria coletiva, aborda a dinâmica da pluralidade da existência e da resistência na preservação de elementos da cultura daqueles territórios, propagada para os destinatários.

Há um grupo significativo de pesquisadores(as) que estudam o acervo de cartas de alguns povos indígenas. A exemplo, COSTA (2018), em seus estudos, argumenta que "o Brasil é o vocativo presente na vontade de conversação por cartas dos indígenas, mas, "ausente" nas respostas, no possível pacto de interlocução que, por vezes, a escrita epistolar exige". Seguida dessa afirmação, reitera que os povos de origens escrevem cartas desde os tempos de colonização. Em tempos mais recentes, eles ampliaram o diálogo por cartas pós a promulgação dos direitos indígenas na Constituição de 1988. No entanto, há uma tentativa vã de correspondência com o interlocutor - Brasil.

Nesse sentido, há um descrédito com os saberes da terra postulados pelas comunidades indígenas. Quando permitimos a perpetuação de posturas etnocêntricas, congratulamos o extermínio 
da memória dos povos indígenas em suas cosmologias de conhecimentos e todas as heranças que delas se constituem, heranças do povo brasileiro.

$\mathrm{Na}$ década de oitenta, algumas composições denunciavam a falta de consciência política do povo brasileiro, sobretudo, no reconhecimento da diversidade cultural. Teciam-se composições viscerais em "Querelas do Brasil” (Maurício Tapajós / Aldir Blanc, 1978), que nos tempos políticos hodiernos, ecoam em contestações de todas as ordens. $\mathrm{Na}$ oportunidade, caros leitores, chamamos atenção para a enorme perda nacional, no campo das Artes, em virtude do falecimento de um dos autores, Aldir Blanc, vítima do novo coronavírus. A sensação que temos é a de que a poesia, que ele tanto cantava e encantava, foi silenciada. Importa bradar, em alto e bom tom, a composição musical, evocando um espírito de luta.

A poesia musical clama por uma identidade nacional em consonância com os povos nativos, evidenciando o descaso com as riquezas culturais. Há um desconhecimento do Brasil-Brasis, o que anula uma consciência identitária. A composição aporta a díade território-territorialidade, agrega potência vital ao rico e valoroso patrimônio cultural. Soma-se a isso, o entreguismo do Brasil aos Estados Unidos da América:

Brazil não conhece o Brasil / O Brasil nunca foi ao Brazil Tapir, jabuti, liana, alamandra, alialaúde / Piau, ururau, aquiataúde Piá, carioca, porekramekrã / Jobim, akarore e jobim açu Oh, oh, oh,

Pererê, camará, tororó, olererê / Piriri, ratatá, karatê, olará O Brazil não merece o Brasil / O Brazil tá matando o Brasil. (In memorian ao inumerável Aldir Blanc+ 04/05/2020 - Querelas do Brasil - 1978).

É tempo de clamar a atenção dos brasileiros para encamparem, junto aos povos indígenas, as lutas pela preservação dos nossos territórios, que sorrateiramente estão no auge das invasões.

Mediante o exposto, retomamos as Experiências Sensíveis que citamos no início desta interlocução, justificando todo o nosso encantamento, vibração e engajamento às culturas nativas.

\section{Carta - Semente}

Em nossas primeiras experiências com as aldeias, ouvimos histórias e partilhamos memórias com os indígenas. Nessa relação de interculturalidade, experienciamos também a língua materna Patxôhã em expressões de oralidades e traduções, resultando em escritas de origens e escritas literárias.

Imagino que vocês estão se perguntando: como tais escritas foram produzidas?

Nosso projeto foi tecido em três etapas: observação, implicação e partilhamento. A observação seria tecer escrita etnográfica durante noventa dias de observação distanciada. 
Posteriormente, a implicação propunha sessões de leituras e contação de obras literárias de autores indígenas, sensibilizando as crianças a comporem escritas de origem. Por último, partilhar as escritas das composições com as aldeias.

Nossa linearidade cronológica caiu por terras indígenas.

Os percursos científicos tomaram outros rumos, e as crianças seguiram outras trilhas. Escreveram cartas endereçadas a nós: "Esta carta é para você!" As cartas eram escritas e ilustradas, nos diversos ângulos do Monte Pascoal, conjugando a paisagem natural com a memória daquele patrimônio.

Nessas escritas, as crianças anunciavam suas identidades Pataxó, assinando seus nomes no fim do documento, (Tamikuã Pataxó), dando-nos intimidade e criando elos de proximidade com suas vidas, trocando diálogos em prol dos saberes locais. Nessa relação próxima, buscamos a unidade de sentidos naquelas representações.

Essa experiência ampliou nossas cosmovisões da cultura Pataxó, uma vez que nosso coletivo acompanhava o grupo de crianças por todo o território e as ações docentes fora da aldeia, juntamente com os pais. Também participamos da mediação de conferências locais da Educação Escolar Indígena e dos jogos Pataxó no encontro da Teia dos Povos. Em todos esses espaços estávamos juntos, envolvidos espiritualmente na identidade Pataxó. Nesse percurso, em todos os tempos sagrados e rituais da aldeia, ouvimos suas histórias e contamos as nossas, construindo conversações formativas, mediadas por literaturas indígenas em consonância com experiências de escritas da terra em autorias coletivas.

A história do povo indígena Pataxó é contada na literatura do Kanátyo Pataxó:

O índio pisou na terra, começou a olhar as florestas [...] fascinado com a beleza que estava vendo ao seu redor. Ele trouxe consigo muita sabedoria sobre a terra. Conhecia época boa de plantar, de caçar, de pescar e as ervas boas de fazer remédios e seus rituais [...]. Um dia, o indio estava fazendo um ritual. Enxergou uma grande chuva. Cada pingo de chuva ia se transformando em um índio. No dia marcado, a chuva caiu. Depois que a chuva parou de cair, o índio reuniu os outros e falou: - Olha parentes, eu cheguei aqui muito antes de vocês, mas agora tenho que partir. Os índios perguntaram: - Pra onde você vai? Eu tenho que ir morar lá em cima no ITÔHÃ, porque tenho que proteger vocês. Os índios ficaram um pouco tristes, mas depois concordaram [...]. Daquele dia em diante, os índios começaram as suas caminhadas aqui na terra, trabalhando, caçando, pescando e fazendo festas. E assim surgiu a nação Pataxó. Pataxó é a água da chuva batendo na terra, nas pedras e indo embora para os rios, para o mar. Pa ta xó. (KANATYO PATAXÓ, 1998, p. 4-12).

Olhar de professor, Ponta Grossa, v. 24, p. I-9, e-15947.067, 2021.

Disponível em <https://revistas2.uepg.br/index.php/olhardeprofessor> 
A língua Pataxó é revigorada na escola e, por vezes, as crianças produzem fluência e constroem facetas com a língua materna. Destacamos um episódio interativo entre Jaciã Pataxó e uma estudante do nosso coletivo de estudo:

- Professora, por que você sempre conta história de índio?

Perguntou a menina Jacian Pataxó à lanka, que respondeu:

- Olha é sempre bom saber sobre nossa cultura.

- Nossa cultura?

Questiona a menina...

- Sim. Eu também sou um pouco indígena.

Responde lanka. A menina diz:

- Ah, se você também é índia, me diz: Você sabe o que é que kijeme? lanka responde:

- Não sei não.

- Se você não sabe o que é kijeme, então você não é índia. Kijeme significa casa! (Notas de campo, 05/12/16).

As cartas iconografadas revelam os "lugares autobiográficos" (KOTRE, 1997). Esses diálogos foram debatidos por diversas vezes no nosso Núcleo de Pesquisa (NUPEEES/GPITI). Essas conversações nos inquietaram em reverberação à cultura Pataxó. $O$ tempo passava em torno destas sementes. Escrevemos artigos, construímos debates, entre outras ações. Tínhamos as sementes, por fim, restava-nos plantar e observar as luas até à colheita.

Mas o fim foi somente o começo.

O autor indígena Ailton KRENAK (2019) vem espalhando "ideias para adiar o fim do mundo". Desse modo, este coletivo também prolonga o fim desta colheita, ampliando diálogos com demais autores indígenas, como: Daniel MUNDURUKU, Edson KAYAPÓ, Davi KOPENAWA e Graça GRAÚNA, nutrindo com estes a nossa árvore reflexiva. Com o povo Guarani/Tupiniquim do Espírito Santo, ampliamos nosso arado, conversamos sobre as origens de diferentes línguas em suas representações sígnicas.

Relembramos que, no passado, o Tupi-Guarani era a língua universal. Construímos uma invenção literária que chamamos de Tupiabá. Esse ato criativo-linguístico proporcionou indagações sobre os nossos processos de aprendizagens com a língua Tupi e a sua influência na língua portuguesa, que nos passa despercebida:

Qual o Tupi que você fala? Sabe que bicho é quando falam sagui, tamanduá ou siri? Sucuri, jacaré, capivara, arara, urubu, tucano, paca ou tatú? [...] Sabe o significado da palavra abacaxi? Então, tudo isso é Tupi. Também é Tupi: sabiá, samambaia e paçoca. E piranha, taquara, perereca, taturana e peteca. (FRAGATA, 2018, p. 8-16).

Nesse universo, a palavra inventada, não inventada, da escrita Tupiabá comporta vivências linguageiras na diversidade das variadas línguas indígenas. O Tupiabá está no Tupi, no tupinambá, no 
tupiniquim, no tupi-guarani, na ponta da língua materna: vem cá piá. O Tupiabá é a inspiração Jubiabá da literatura de Jorge Amado (2008), composta em sua cartilha do feiticeiro, que orienta o afrobrasileiro em suas subversões. Inspira a fruição oral imaginária da afro-brasilidade implicada com a cultura indígena, remetendo-nos a uma espiritualidade xamã, significativo literário que amplifica e justifica nossos projetos originários.

Por que criar o Tupiabá? Para valorizar escritas de projetos que validam conhecimentos de origens, conhecimentos que valorizem as iniciativas produtivas dos povos indígenas, que potencializam a história e memória nas pertenças identitárias na diversidade, possibilitando reconhecer essas populações em seus modos de produção, de trabalho e vida, fomentando processos e valores almejados à equidade social.

Nessa perspectiva, criamos, a partir do mês de comemoração dos povos indígenas, o site institucional intitulado TUPIABÁ: Projetos Originários. A divulgação aconteceu no dia 19 de abril de 2020, com o projeto Cartas do mundo para os(as) guardiões(ãs) da Terra, mobilizando articulações em defesa da vida dos povos indígenas em tempos de novo coronavírus.

As cartas-mundo para as crianças indígenas serão encaminhadas via correio eletrônico, no site Tupiabá. Entre os inúmeros acessos recebidos em nossa plataforma, já foram encaminhadas muitas cartas, contendo indagações planetárias em torno das nossas corresponsabilidades de cuidar da terra, tais como estes guardiões. Uma particularidade do nosso projeto é que as aldeias não possuem acesso à rede mundial de computadores. Essas cartas serão impressas e enviadas para as aldeias.

Caros leitores, vocês devem estar se questionando: como essas cartas chegarão até lá? Será que as cartas vão a cavalo? Ou pelas asas do pombo correio?

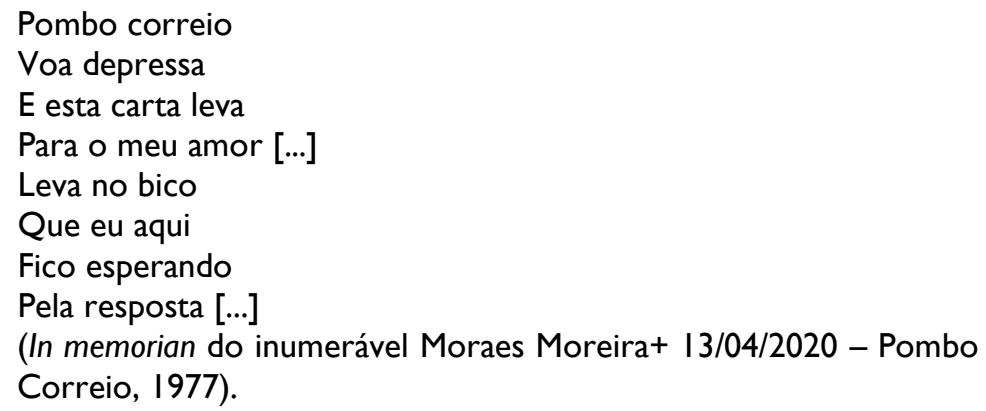

Entramos "Juntos" nestes territórios com a "Cara e Coração" numa "Transversal do Tempo". Tempo de catástrofe! Para este coletivo, a transversalidade anunciada aponta que os tempos são outros. E os outros, é "Quanta".

Neste tempo, qual é sua cosmovisão? Escreva para aldeia!

Atenciosamente, Coletivo Tupiabá! 


\section{Referências}

ALMEIDA, M. I. de. Desocidenta: experiência literária em terra indígena. Belo Horizonte: Ed. UFMG, 2009.

AMADO, J. Jubiabá. São Paulo: Editora Companhia das Letras, 2008.

CASCUDO, C. Dicionário do folclore brasileiro. São Paulo: Ediouro Publicações S/A, 1972.

COSTA, S. L. As cartas dos povos indígenas ao Brasil: a construção do arquivo 2000 - 2015.

Memória americana: cuadernos de etnohistoria. Buenos Aires: UBA, v. 26, n. I, p. 94-104, 2018. Disponível em: http://revistascientificas.filo.uba.ar/index.php/MA/article/view/6205. Acesso em: 20/05/2020.

FRAGATA, C. O tupi que você fala. São Paulo: Globo Livros, 2018.

KAYAPÓ, E. Pod Cast da série Mekukradjá. São Paulo. Itaú Cultural. Dezembro, 2019. Disponível em: https://www.itaucultural.org.br/edson-kayapo-mekukradja. Acesso em: 15/05/2020.

KOPENAWA, D. ALBERT, B. A queda do Céu: palavras de um xamã Yanomami; tradução Beatriz Perrone-Moisés; prefácio de Eduardo Viveiro de Castro. I a ed. São Paulo: Companhia das Letras, 2015.

KOTRE, J. Luvas brancas: como criamos a nós mesmos através da memória. São Paulo: Mandarin, 1997.

KRENAK, A. Ideias para adiar o fim do mundo. São Paulo: Companhia das Letras, 2019.

LUZ, M. A. Pensamento insurgente: direito a alteridade, comunicação e educação. $I^{\mathrm{a}}$ ed. Salvador: Editora EDUFBA, 2018.

MIRANDA, M. R. Índio Pataxó o que vem fazer aqui? Autorias de Infâncias na aldeia Pé do Monte. Anais do Seminário Nacional Infâncias: Infâncias luventudes e cidades - Um diálogo com a educação. Vitória/ES: Universidade Federal do Espírito Santo - Programa de Pós-graduação da UFES, 20I7. v. I. p. OI-II2.

MIRANDA, M. R. Você sabe o que é kijeme? Vitória/ES: Edições da autora, 2017.

MIRANDA, M. R. Aranã e a Cacimba. Vitória/ES: Edições da autora, 2018.

MUNduruKu, D. Comentário do Pod Cast do Ajuru Pataxó da série Mekukradjá. Itaú Cultural. Outubro, 2019. Disponível em: https://www.itaucultural.org.br/daniel-mundurukumekukradja. Acesso em: 15/05/2020.

MUSEU DO ÍNDIO FUNAI - RJ. Catálogo de exposição fotográfica Tempo de Escrita Espaço Muro do Museu, 2008.

NOVO TEMPO. Intérprete Ivan Lins. Compositor: Ivan Lins/Vitor Martins. In: JUNTOS. Intérprete: Ivan Lins. Rio de Janeiro: Philips Records, 1984. Formato I cd, faixa 5, duração 4:I3.

PATAXÓ, K. Txopai e Itôhã. Programa de implantação das escolas indígenas de Minas Gerais, SEE/MG - Belo Horizonte, 1998. 
PATAXÓ, K. Txopai e Itôhã. Entrevista concedida a Maria Inês de Almeida por ocasião da formatura da I ${ }^{a}$ turma do curso de Magistério Indígena do PIEI-MG. Parque Estadual do Rio Doce, 1989.

PELA INTERNET. Intérprete Gil Gilberto. Compositor: Gilberto Gil. In: QUANTA. Intérprete: Gilberto Gil. Rio de Janeiro: Warner Music, 1997. Formato 2 cd, cd I, faixa II, duração 4:05.

POMBO CORREIO. Intérprete Moraes Moreira. Compositor: Moraes Moreira. In: CARA E CORAÇÃO. Intérprete: Moraes Moreira. Rio de Janeiro: Som livre, 1977. Formato I disco vinil, lado A, faixa 2, duração 2:4l.

QUERELAS DO BRASIL. Intérprete Elis Regina. Compositor: Blanc, A./Tapajós, M. In: TRANSVERSAL DO TEMPO. Intérprete Elis Regina. Rio de Janeiro: Phonogran, 1978. Formato I disco vinil, lado B, faixa 9, duração 3:49.

TUPIABÁ, Projetos Originários. Cartas para a aldeia. Cartas dos(as) guardiões(ãs) da Terra e do Céu: experiências de escritas originárias das crianças indígenas para o mundo. Disponível em: http://projetotupiaba.com.br. Acesso em: 20 de maio 2020.

Recebido em: I 3 de junho de 2020.

Versão corrigida recebida em: 28 de setembro de 2020.

Aceito em: 21 de outubro de 2020.

Publicado online em: 26 de junho de 2021. 